\title{
Mortality rates from multiple sclerosis: geographical and temporal variations revisited
}

\author{
Edward S Williams, David R Jones, Ronald O McKeran
}

\begin{abstract}
A review of the United Kingdom (UK) multiple sclerosis (MS) literature suggests that over the last three decades prevalence and estimated incidence rates have increased, while mortality rates have been declining. UK mortality data over a 30 year period have been studied to examine temporal and geographical variations, to estimate changes in survival, and to examine the relationship between mortality and morbidity trends. The study has shown an overall decline in mortality throughout the UK of approximately $25 \%$ over the 30 year period ending in 1983, and a reduction in the mortality differential between Scotland, and England and Wales, but no positive correlation has been found between mortality and morbidity. The overall decline in death rate in females was $23 \%$ and in males $30 \%$ over the $\mathbf{3 0}$ years of the survey. The total number of deaths declined by $39 \%$ between the five year periods 1954-58 and 1979-83 in Scotland compared with a $10 \%$ decline for England and Wales. Estimated median age of death increased from 52 to 59 years and the improvement in survival over the period of study was similar for both countries and is unlikely to have contributed to the reduction in mortality differential. Within England and Wales regional mortality rates did not show a clear north-south gradient. The decline in the mortality differential between Scotland and England (if not artefactual) may provide an important aetiological clue in the search for the cause of multiple sclerosis, and the rate of decline suggests an environmental rather than a genetic aetiology.
\end{abstract}

Since Limburg hypothesised almost 40 years ago that the frequency of multiple sclerosis (MS) is related to the distance of the surveyed area from the equator, ${ }^{1}$ epidemiological research seeking clues to the aetiology of the disease has been dominated by consideration of the geographic distribution of the disease. In the early 1950s, for example, McAlpine and Compston's study of United Kingdom (UK) mortality rates supported the idea of a north-south gradient, ${ }^{2}$ and several subsequent prevalence surveys have also given support to the idea that Limburg's theory holds for the UK (table 1). . $^{3-13}$ Recently Swingler and Compston have suggested that the gradient in prevalence in the UK correlates with regional differences in the frequency distribution of HLA-DR2 antigens in normal individuals. ${ }^{14}$

An examination of temporal trends in multiple sclerosis may, however, be important in the search for aetiological factors. An analysis of UK prevalence surveys show two interesting trends. Firstly, surveys done in the 1980s record prevalence rates which are substantially higher than rates recorded in the 1950 s. For example, an early survey in North West Scotland (1954) recorded a prevalence of 67 per $100000^{5}$ whereas a recent survey in south London (1986) recorded a rate of $115 .{ }^{13}$ Secondly, prevalence has increased in each area in the UK which has been studied more than once. Three surveys of North East Scotland carried out in the 1970s produced rates of 127, 144 and 178 per 100000 respectively. ${ }^{9-11}$ An examination of indirectly estimated incidence rates shows a clear temporal trend with the more modern surveys producing higher incidence rates than earlier surveys. In North East Scotland estimates of the incidence rates have increased from 3.0 per 100000 per annum in 1953, to 5.3 in early 1970 , to $7 \cdot 5$ in the late 1970 s. $^{5911}$

A recent review of UK mortality data, on the other hand, has shown a significant decline in mortality throughout the UK between $1921-80 .{ }^{14}$ While an increase in survival will lead to an increase in prevalence with a corresponding decrease in mortality over the short term, it is not clear to what extent changes in survival account for the changes in prevalence described above.

The epidemiological picture of multiple sclerosis in the UK is therefore somewhat unclear with morbidity and mortality data showing temporal disease trends going in apparently different directions. To describe temporal and geographical trends in mortality we have studied UK mortality data over a 30 year period. The objectives of the survey were: 1) to examine temporal and geographical variations in mortality; 2) to estimate changes in survival as far as is possible from the available data, and 3) to examine the relationship between mortality and morbidity trends.

\section{Methods}

Annual numbers of deaths attributed to multiple sclerosis (as underlying cause) ${ }^{1516}$ and estimates of population in England and Wales, Scotland and Northern Ireland were taken from published sources for the period 1954-83, 
Table 1 Summary of major United Kingdom prevalence surveys of multiple sclerosis 1950-86

\begin{tabular}{|c|c|c|c|c|c|}
\hline Area & $\begin{array}{l}\text { Year of } \\
\text { survey }\end{array}$ & $\begin{array}{l}\text { Surveyed } \\
\text { population }\end{array}$ & Cases & $\begin{array}{l}\text { Crude prevalence) } \\
100000(95 \% \\
\text { Confidence } \\
\text { intervals) }\end{array}$ & $\begin{array}{l}\text { Standardised } \\
\text { prevalence } \\
\text { ratio }\end{array}$ \\
\hline Northern Ireland ${ }^{34}$ & 1951 & 1370709 & 700 & $51(47-55)$ & 62 \\
\hline North Scotland ${ }^{5}$ & $\begin{array}{l}1961 \\
1954\end{array}$ & $\begin{array}{r}1425042 \\
231116\end{array}$ & $\begin{array}{r}1158 \\
154\end{array}$ & $\begin{array}{l}81(77-86) \\
67(56-77)\end{array}$ & $\begin{array}{r}100 \\
76\end{array}$ \\
\hline Cornwall $^{12}$ & 1958 & 338770 & 214 & $63(54-72)$ & 68 \\
\hline Durham and Northumberland ${ }^{6}$ & 1959 & 2308000 & 1156 & $50(47-53)$ & 56 \\
\hline Orkney ${ }^{578}$ & $\begin{array}{l}1954 \\
1962\end{array}$ & $\begin{array}{l}20746 \\
18531\end{array}$ & $\begin{array}{l}23 \\
33\end{array}$ & $\begin{array}{l}111(65-156) \\
178(117-239)\end{array}$ & $\begin{array}{l}124 \\
200\end{array}$ \\
\hline & 1970 & 17007 & 40 & $234(161-307)$ & 284 \\
\hline & 1974 & 17462 & 54 & $309(227-391)$ & 384 \\
\hline Shetland 578 & 1954 & 18715 & 25 & $134(81-185)$ & 142 \\
\hline & 1962 & 17537 & 29 & $165(105-226)$ & 184 \\
\hline & 1970 & 17327 & 31 & $179(116-242)$ & 216 \\
\hline & 1974 & 18445 & 34 & $184(122-246)$ & 237 \\
\hline North East & 1970 & 440176 & 557 & $127(116-137)$ & 153 \\
\hline Scotland $d^{9-11}$ & 1973 & 440227 & 634 & $144(133-155)$ & 175 \\
\hline & 1980 & 471000 & 839 & $178(165-190)$ & 221 \\
\hline London Borough of Sutton ${ }^{13}$ & 1985 & 169600 & 195 & $115(99-131)$ & 129 \\
\hline
\end{tabular}

^Based on prevalence rates in the 1961 Northern Ireland study. ${ }^{4}$

for each sex and age group 15-34, 35-44, 4554, 55-64 and 65 and over. ${ }^{17}$ Corresponding annual death and population data were collected for the nine standard English regions, for the period 1974-83.

Annual age and sex specific death rates per 100000 population were calculated for England and Wales, Scotland and Northern Ireland for the period 1954-83. Standardised mortality ratios (SMRs) were calculated for England, Scotland and Northern Ireland for the same period, using 1974 death rates in the UK as standard.

Poisson regression models ${ }^{18}{ }^{19}$ were used in assessing linear trends in mortality rates with calendar period, and in examining the interrelationship between variations with area, calendar period and age group. The model reported is equivalent to assuming that the number of observed deaths $\mathrm{O}_{\mathrm{ijk}}$ in the ith age group $(\mathrm{i}=1, \ldots 6: 15-34,35-44,45-54$, $55-64,65-74,75+)$, $j$ th country $(j=1,2,3$ : England and Wales, Scotland, Northern Ireland) and $k$ th year $(k=1, \ldots .30: 1954$, $\ldots, 1983)$ are independent Poisson variables whose means satisfy: $\log \mathrm{E}\left(\mathrm{O}_{\mathrm{ijk}}\right)=\log \left(\mathrm{P}_{\mathrm{ijk}}\right)+$ constant $+\alpha_{i}+\beta_{i} \mathrm{x}+\alpha_{i}^{\prime}+\beta_{j}^{\prime x}$ where $P_{i j k}$ is the number of person years at risk ${ }^{20}$ in the $i-j-$ $k$ th category and $x$ the time in years from 1953; autocorrelation between observations in successive years is thus ignored. Age groupcalendar period of death-birth cohort effects were investigated by following a variety of approaches, ${ }^{2122}$ using cohorts defined by 10 year age groups and calendar periods.

\section{Results}

MORTALITY BY AGE, SEX AND CALENDAR PERIOD OF DEATH

The number of MS deaths at age 15 and over recorded in England and Wales, Scotland and Northern Ireland from 1954-83 and corresponding crude death rates are shown in table 2 . In all three countries the male:female mortality ratio is approximately $2: 3$, in accordance with previous accounts ${ }^{23}$ of the epidemiology of MS. Apparently higher rates in Scotland and Nor- thern Ireland than in England and Wales agree with the latitudinal hypothesis.

However, as figs 1 and 2 show there are clear time trends over the thirty year period and marked variations in mortality between age groups. From fig 1 it is apparent that crude death rates have fallen over the thirty year period in the UK as a whole. The female death rate at ages 15 and over declined from 3.2 per 100000 in 1954 to 2.45 in 1983 , a fall of about $23 \%$; the male death rate declined from $2 \cdot 3$ to $1 \cdot 6$, a fall of about $30 \%$. These findings are confirmed by the decline in the number of deaths set out in table 3 . From this table it is clear that the fall has been much more marked in Scotland (39\% between the first and last five year periods shown) and possibly also in Northern Ireland $(27 \%)$ than in England and Wales $(10 \%)$.

The main features of the death rates for females in England and Wales in fig 2 are that 1) the highest death rates have been seen in the 45-64 year age group; 2) in both this group and the 15-44 age group death rates have been declining steadily through the period, but 3 ) rates in the $65+$ group have been increasing.

Similar patterns appear to be present in the results for Scotland with the important exception that rates in the over $65 \mathrm{~s}$ would seem to have declined somewhat, explaining the sharper overall decline seen in table 3. In Northern Ireland the scatter of annual rates is much wider, the rates being based on much smaller numbers than in England and Wales, and clear trends are difficult to discern. In the corresponding male mortality rates the separation of

Table 2 Number of deaths, and average annual death rates per 100000 from multiple sclerosis at age 15 and over, 1954-83, by country and sex

\begin{tabular}{llrllr}
\hline & \multicolumn{2}{l}{ Males } & & \multicolumn{2}{l}{ Females } \\
\cline { 2 - 3 } \cline { 6 - 6 } \cline { 6 - 6 } & Rate $/ 10^{5}$ & Deaths & & Rate $/ 10^{5}$ & Deaths \\
\hline England and Wales & 1.77 & 9370 & & 2.59 & 15023 \\
Scotland & 2.79 & 1543 & & 3.66 & 2272 \\
Northern Ireland & 2.71 & 415 & 3.62 & 598 \\
United Kingdom & 1.91 & 11328 & & 2.72 & 17893 \\
\hline
\end{tabular}


Figure 1 Mortality from multiple sclerosis in the United Kingdom by sex at age 15 and over: 1954-83.

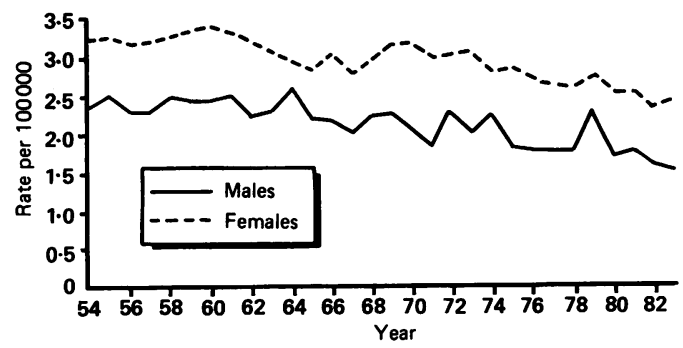

Figure $2 a$ Mortality rate per 100000 per year 1954-83, females, by age group: England and Wales.

Figure $2 b$ Mortality rate per 100000 per year, females by age group:

Scotland.

Figure 2c Mortality rates per 100000 per year females by age group: $N$ Ireland.

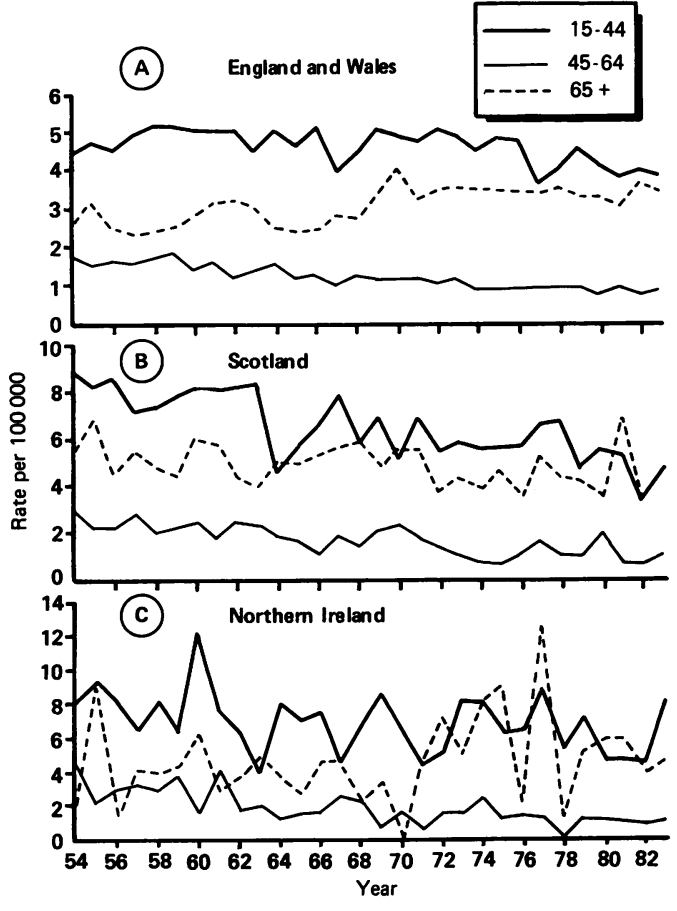

Table 3 Deaths from multiple sclerosis in five year periods 1954-83, by country

\begin{tabular}{rcccc}
\hline & England and Wales & Scotland & Northern Ireland & United Kingdom \\
\hline $1954-58$ & 4129 & 810 & 200 & 5139 \\
$59-63$ & 4312 & 769 & 189 & 5270 \\
$64-68$ & 4044 & 628 & 147 & 4819 \\
$69-73$ & 4293 & 591 & 160 & 5044 \\
$74-78$ & 3888 & 529 & 169 & 4586 \\
$79-83$ & 3701 & 492 & 145 & 4338 \\
$1954-83$ & 24367 & 3819 & 1010 & 29196 \\
\hline
\end{tabular}

Table 4 Standardised mortality ratios (and 95\% confidence intervals) for multiple sclerosis by sex, country and selected years 1954-83

\begin{tabular}{lccc}
\hline & England and Wales & Scotland & Northern Ireland \\
\hline & & Females & \\
1954 & $103(94-112)$ & $202(165-245)$ & $217(143-315)$ \\
1964 & $105(96-114)$ & $118(91-151)$ & $142(85-222)$ \\
1974 & $96(88-105)$ & $108(82-139)$ & $201(134-290)$ \\
1983 & $89(81-97)$ & $79(57-106)$ & $90(48-155)$ \\
& & Males & \\
1954 & $99(89-111)$ & $222(175-277)$ & $197(115-316)$ \\
1964 & $109(89-121)$ & $166(126-215)$ & $98(45-186)$ \\
1974 & $97(87-108)$ & $116(83-158)$ & $157(88-259)$ \\
1983 & $67(59-76)$ & $90(61-126)$ & $131(70-255)$ \\
\hline
\end{tabular}

United Kingdom $1974=100$. death. rates is potentially misleading ${ }^{22}$ but SMRs for every tenth year during the study period are presented for reference in table 4 . Deaths at ages 65 and over account for about $22 \%$ of those at all ages from MS in the UK. Consequently whereas the overall impression of time trends in mortality rates in Scotland and Northern Ireland is downwards as the summary SMRs in table 4 indicate, in England and Wales the opposite age specific trend have largely compensated each other. The sharper decline in SMRs in Scotland and Northern Ireland than in England and Wales over the period corresponds to a narrowing of differentials in overall mortality over the period.

All of these descriptive results are confirmed and shown more clearly by the results of Poisson regression analysis of the data. The coefficients of a model for female mortality comparing age group, country, and time trend terms are shown in table 5 . The intercept coefficients clearly show that death rates are higher in Scotland and Northern Ireland than in England and Wales, and suggest that they are highest in the 45-54 and 55-64 age groups. There is evidence for an overall downward trend with time in all age groups except 65-74 and $75+$ and steeper declines in Scotland and Northern Ireland than in England and Wales. Results of a corresponding model for male mortality are very similar.

\section{ANALYSIS OF BIRTH COHORT EFFECTS IN} MORTALITY

In the previous section analyses of variations in MS mortality rate with calendar period have been reported. However, without further possibly arbitrary assumptions such effects are not distinguishable from those attributable to variations between birth cohorts, ${ }^{21} 22$ and thus interpretation of the data and of the regression models may be problematical. (A linear drift is clearly identifiable, but second order non drift effects do not show a clear pattern.) Nonetheless, one interpretation of the results of a Poisson regression model incorporating only age and cohort terms is that mortality is considerably lower in cohorts whose birth centred around 1938, and in later cohorts, than in the earlier cohorts. This is consistent with the pattern of cohort specific rates for England and Wales presented by $\mathrm{Li}$ et al. ${ }^{24}$

\section{CUMULATIVE MORTALITY}

Cumulative mortality for the five year periods 1954-58 and 1979-83 are presented in table 6. Whereas $60 \%$ of the MS population of the UK had died by age 55 in the earlier period, only $39 \%$ had died in the more recent period, suggesting longer survival. Estimated median ages at death were 52 in 1954-58, and 59 in 1979-83. Changes in cumulative mortality between 1954-58 and 1979-83 were similar in the three countries. Thus on the further assumption that median ages of onset are similar in each country, (estimated to be around 34 years in various prevalence surveys $)^{61013}$ and that the age at onset had not changed during the period of the survey, it follows that survival experiences have changed 
at approximately the same rate in all three countries.

\section{MORTALITY BY REGION}

Mortality data by standard region for each of the ten years $1974-83$ by age group and sex as before have been examined in similar ways. Numbers of deaths by region are, however, so small that age specific trends are difficult to identify graphically. The results of Poisson modelling as before (with region replacing country) are summarised in table 7. Standardised mortality ratios for the 10 year period by region are shown in table 8 . Neither analysis offers evidence supporting the existence of a

Table 5 Parameter estimates from Poisson regression models of observed deaths in females by country, year and age group

\begin{tabular}{lcc}
\hline Factor & Intercept (SE) & Time trend (SE) \\
\hline Constant & $-4.85(0.06)$ & $-0.03(0.003)$ \\
Age group (vs 14-34 group) & & \\
35-44 & $1.49(0.07)$ & $0.006(0.004)$ \\
$45-54$ & $1.91(0.06)$ & $0.017(0.004)$ \\
$55-64$ & $1.83(0.06)$ & $0.029(0.004)$ \\
$65-74$ & $1.44(0.07)$ & $0.041(0.004)$ \\
$75+$ & $0.51(0.10)$ & $0.047(0.005)$ \\
Country (vs England and Wales) & $0.55(0.04)$ & $-0.014(0.003)$ \\
Scotland & $0.53(0.08)$ & $-0.009(0.005)$ \\
Northern Ireland &
\end{tabular}

Deviance 634.5 on $524 \mathrm{df}$

(Null model deviance 10615 on $539 \mathrm{df}$ ).

Table 6 Cumulative mortality by age group and country for periods 1954-58 and $1979-83$

\begin{tabular}{lllll}
\hline \multicolumn{5}{c}{$\begin{array}{c}\text { Cumulative percentage deaths } \\
\text { 1954-58 }\end{array}$} \\
\hline By age & $\begin{array}{l}\text { Scotland } \\
(n=809)\end{array}$ & $\begin{array}{c}\text { England and Wales } \\
(n=4129)\end{array}$ & $\begin{array}{l}\text { Northern Ireland } \\
(n=200)\end{array}$ & $\begin{array}{l}\text { United Kingdom } \\
(n=5138) \\
35\end{array}$ \\
10 & 9 & 11 & 9 \\
45 & 26 & 29 & 35 & 29 \\
55 & 58 & 60 & 68 & 60 \\
65 & 83 & 84 & 87 & 84 \\
75 & 96 & 97 & 96 & 96 \\
& & & & \\
& $(n=492)$ & $(n=3671)$ & $(n=145)$ & $(n=4308)$ \\
35 & 6 & 6 & 5 & 6 \\
45 & 20 & 17 & 19 & 18 \\
55 & 38 & 38 & 46 & 69 \\
65 & 68 & 69 & 68 & 91 \\
75 & 90 & 91 & 88 & \\
\hline
\end{tabular}

Table 7 Parameter estimates from Poisson regression model of observed deaths in females by region, year and age group

\begin{tabular}{|c|c|c|}
\hline Factor & Intercept (SE) & Time trend ( $S E)$ \\
\hline Constant & $-5 \cdot 51(0 \cdot 14)$ & $0.002(0.021)$ \\
\hline $\begin{array}{l}\text { Age group (vs 14-35 group) } \\
35-44 \\
45-54 \\
55-64 \\
65-74 \\
75+\end{array}$ & $\begin{array}{l}1.65(0.16) \\
2.56(0.14) \\
2.55(0.14) \\
2.44(0.14) \\
1.45(0.17)\end{array}$ & $\begin{array}{r}-0.026(0.025) \\
-0.057(0.023) \\
-0.013(0.022) \\
-0.009(0.023) \\
0.026(0.027)\end{array}$ \\
\hline $\begin{array}{l}\text { Region (vs South East) } \\
\text { North West } \\
\text { East Midlands } \\
\text { West Midlands } \\
\text { East Anglia } \\
\text { Yorkshire } \\
\text { South West } \\
\text { Wales } \\
\text { Northern } \\
\text { Scotland }\end{array}$ & $\begin{array}{r}0.07(0.10) \\
-0.04(0.13) \\
-0.04(0.13) \\
-0.20(0.17) \\
-0.19(0.11) \\
-0.02(0.11) \\
-0.35(0.16) \\
-0.13(0.13) \\
0.15(0.13)\end{array}$ & $\begin{array}{c}-0.026(0.017) \\
-0.002(0.021) \\
0.045(0.019) \\
0.039(0.027) \\
0.027(0.018) \\
0.0001(0.019) \\
0.008(0.026) \\
0.026(0.021) \\
-0.003(0.022)\end{array}$ \\
\hline
\end{tabular}

Deviance 578.8 on 540 df.

(Null model deviance $3708 \cdot 4$ on $569 \mathrm{df}$ ).
Table 8 Standardised mortality ratios (and 95\% confidence intervals) from multiple sclerosis by sex and region, $1974-83$

\begin{tabular}{lcc}
\hline & \multicolumn{1}{l}{ Males } & \multicolumn{1}{l}{ Females } \\
\hline Yorkshire & $106(94-118)$ & $98(89-107)$ \\
Northern & $95(82-110)$ & $103(92-116)$ \\
North West & $96(86-106)$ & $96(88-103)$ \\
East Midlands & $96(84-110)$ & $97(87-108)$ \\
West Midlands & $84(74-95)$ & $88(80-97)$ \\
East Anglia & $95(78-115)$ & $104(89-120)$ \\
South East & $100(94-106)$ & $102(97-107)$ \\
South West & $92(81-104)$ & $100(91-110)$ \\
Wales & $86(73-102)$ & $75(65-86)$ \\
Scotland & $139(126-154)$ & $124(114-134)$ \\
\hline
\end{tabular}

north-south gradient in mortality within England, although the SMRs for Scotland are raised. Other differentials and trends in the model are consistent with those to be expected from the country based model in table 5 . The most interesting feature of the SMRs in table 8 is the occurrence of apparently low levels of mortality from MS in the West Midlands and in Wales. There is some corroboration for these findings in the model results in table 7 , although the strong upward trend with time in the West Midlands should be noted. The results of a corresponding model for male mortality are less clear.

\section{MULTIPLE SCLEROSIS AS UNDERLYING AND} CONTRIBUTORY CAUSE OF DEATH

The data used in this study are based on MS recorded as the underlying cause of death on the certificate. Other mentions of MS (as a contributory cause of death) have not been coded routinely throughout the study period and so do not appear in published data.

The coding of all mentions of a particular cause of death (multi-cause) began in 1972 in England and Wales on a sample of certificates. In 1977, for example, of 1030 certificates on which MS was mentioned as a cause of death, 707 had MS recorded as the underlying cause, suggesting that use of an underlying cause alone underestimates deaths of MS sufferers by about $30 \%$. In 1985 the percentage of underlying deaths was again $70 \%$ of all mentions of MS on death certificates. ${ }^{24}$ In Scotland the percentage of MS mentions which are coded as underlying cause also appears to be quite constant over time, with 1017 out of 1970 $(52 \%)$ being recorded as an underlying cause in the period $1975-84 .^{25}$

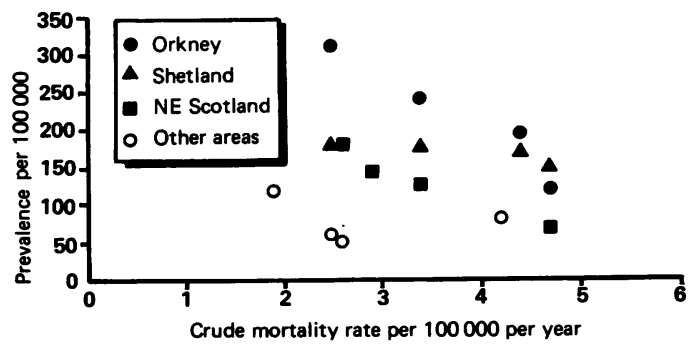

Figure 3 Prevalence ratios and crude mortality rates per 100000 by area over time. 
MORTALITY RATES AND PREVALENCE RATIOS BY AREA AND TIME PERIOD

As fig 3 shows, although no overall relationship between crude prevalence ratios reported in the UK surveys summarised in table 1 and the best contemporary estimate of mortality in the same area can be seen, there are some clear within area time trends. These are particularly apparent for the North (East) Scotland and Orkney rates, but not for the Shetland rates. It should be noted firstly, however, that the mortality rates used for all of these area comparisons are those for the whole of Scotland (more local rates being unobtainable, or subject to large variance) and secondly that the prevalence ratios are themselves subject to wide sampling errors.

\section{Discussion}

The most important findings of this study are: 1) an overall decline in mortality throughout the UK of about $25 \%$ over the 30 year period ending in $1983 ; 2$ ) a reduction in the mortality differential between Scotland on the one hand and England and Wales on the other; 3) no positive correlation between morbidity and mortality.

\section{OVERALL DECLINE IN MS MORTALITY}

This study has demonstrated an overall decline in MS death rates for females of $23 \%$ and for males of $30 \%$ over the 30 years of the survey. One possible explanation for the decline in mortality is that the observed trend may not be real but artefactual. Changes may have occurred in the recognition or diagnosis of the disease, in the way doctors certify MS, or in the rules and procedures for the coding of the disease. In fact there is no evidence to suggest that any of these factors have contributed to the decline. On the contrary, improvements in diagnostic techniques and an increase in awareness of the disease are more likely to have led to an increase in the number of cases diagnosed.

Factors which would cause a real decline in mortality include an improvement in survival over the short term or a true decrease in the incidence of the disease. While the data used in this survey do not permit a true calculation of survival times because there is no clear and well defined starting point, nevertheless, certain inferences about survival can be made if one assumes little change in the median age of onset as Limburgh suggests. ${ }^{1}$ Moreover, a number of UK prevalence surveys have shown the average age of onset to be around 34 years, ${ }^{61013}$ and there is no clear evidence, to suggest any significant change over time. Assuming then the age of onset to be constant over the period of the survey, the data in table 6 suggest an improvement in median survival over the period of the survey which would have contributed to the overall decline in mortality.

\section{REDUCTION IN MORTALITY DIFFERENTIAL} BETWEEN SCOTLAND, AND ENGLAND AND WALES The fact that Scotland has relatively high rates of MS compared with England and Wales is consistent with Limburgh's latitudinal hypothesis. In this survey, however, a clear reduction in the mortality differential between Scotland, and England and Wales has been shown. The total number of deaths (table 3) declined by $39 \%$ between 1954-58 and 197983 in Scotland compared with a $10 \%$ decline for England and Wales. The estimated improvement in survival over the period of the study, however, is similar for both countries (table 4), and so is unlikely to have contributed to the reduction in mortality differential.

The possibility that artefactual factors, such as changes in diagnostic criteria, disease awareness, and in certifying and coding practice, play a role again needs to be mentioned. It is possible that differences in these factors have led to biases in the collection of MS data between England and Scotland which may have contributed to the observed trends. A validation study comparing death certification with clinical data is needed to clarify this question. Nevertheless, it remains possible that a real decrease in the incidence of MS has occurred in Scotland. If this is indeed the case then it could provide an important aetiological clue to the cause of MS. Moreover, in view of the short time scale of change, any dissipating aetiological agent responsible for the diminishing latitudinal gradient is likely to be environmental rather than genetic.

RELATIVE VALUE OF MORTALITY AND MORBIDITY DATA

Another major question that is raised by the findings of this survey is the relative value of mortality and morbidity data. In this survey we found no overall positive correlation between mortality and morbidity data. The overall trend in mortality during the period of study showed a gradual decline in the numbers of $M S$ cases coded as underlying cause, the fall being about $25 \%$ over the 30 year period. Morbidity surveys, on the other hand, demonstrated large increases in incidence and prevalence during the 30 years of the survey. In the north of Scotland, for example, prevalence increased threefold. ${ }^{511}$ During the same time period the SMR in Scotland fell by more than half. The previously reported findings that mortality and morbidity data correlate have not been confirmed by this survey. ${ }^{23}$

Reliance on mortality data may, however, lead to underestimation of prevalence. Published mortality data are based on underlying cause and where MS is certified as a contributing cause of death it is not routinely coded. The resulting degree of underestimation was shown to be around $30 \%$ for England and Wales and nearly $50 \%$ for Scotland. As demonstrated in this paper the proportion of underestimation appears to be consistent over time for both countries, and so mortality data based on underlying cause can be a valuable tool for observing trends and uncovering geographical difference.

Mortality data have two strengths: its completeness, as virtually all deaths are certified and coded, and the reliability of the diagnosis (the doctor is unlikely to mention MS on the certificate unless the diagnosis has been estab- 
lished with reasonable certainty). A further obvious advantage is that mortality data is collected on a routine basis, and so are widely available.

Morbidity (prevalence) data, on the other hand, suffers from incomplete geographic availability and from the disadvantage of diagnostic uncertainty. This is especially likely to be a problem in early cases as there is no definite confirmatory test which is positive in all cases. It seems possible that, under survey conditions where the aim is to ascertain cases, there is a danger of over diagnosing. Therefore diagnostic bias as a result of case finding, although it has never been measured, remains a possibility. Changes in diagnostic habits and different methods of ascertainment make comparisons between population surveys carried out at different times extremely difficult to interpret.

\section{LATITUDINAL GRADIENT?}

In his paper on the prevalence of MS in northern Scotland, Sutherland suggested MS was more common in Scotland than elsewhere in the UK. ${ }^{5}$ This view has been generally accepted, having been supported by the numerous population studies which make Scotland the most surveyed area in the world..$^{7-11}$ Recently, however, Williams and McKeran in studying prevalence in South London questioned the extent of the northsouth gradient. ${ }^{13}$

This review provides evidence that the differential in mortality between Scotland and England has been declining during the survey period. Also there is no clear evidence of a latitudinal gradient in mortality south of the Scottish border.

If it is accepted that at the beginning of the survey period a real north-south gradient existed, then it seems plausible that an environmental factor has been operating to cause the gradient, and that its effect has been dissipating over time, more markedly in Scotland than England. The possibility, however, that an artefact was responsible for the original mor- tality differential between England and Scotland cannot be excluded.

1 Limburg CC. The geographic distribution of multiple sclerosis and its estimated prevalence in the United States. Proc Association for Research into Nervous and Mental Disease 1950;28:15-24.

2 McAlpine D, Compston ND, Lumsden CE. Multiple Sclerosis. London: Livingston, 1955.

3 Allison RS, Millar JHD. Prevalence of disseminated sclerosis in Northern Ireland. Ulster Med J 1954;23:5-27.

4 Millar JDH. Multiple sclerosis in Northern Ireland. In: Clifford Rose F, ed. Clinical epidemiology. Tunbridge Clifford Rose F, ed. Clinical epidemi

5 Sutherland JM. Observations on the prevalence of multiple sclerosis in northern Scotland. Brain 1956;79:635-54.

6 Poskanzer DC, Schapira K, Miller H. Epidemiology of multiple sclerosis in the counties of Northumberland and Durham. J Neurol Neurosurg Psychiatry 1963;26:368-76.

7 Fog M, Hyllested K. Prevalence of disseminated sclerosis in Faroes, the Orkneys and Shetlands. Acta Neurol Scand 1966;42(suppl 19):9-11.

8 Poskanzer DC, Preaney LB, Sheridon JL, Kondy JY. Multiple sclerosis in the Orkney and Shetland Islands: epidemiology, clinical factors and methodology. Epidemiol Community Health 1980;34:229-39.

9 Shepherd DI, Downie AW. Prevalence of MS in north-east Scotland. BMJ 1978;ii:314-6.

10 Shepherd DI, Downie AW. A further prevalence study of multiple sclerosis in north-east Scotland. $J$ Neurol Neurosurg Psychiatry 1980;43:310-5.

11 Downie AW. The Chief Scientist reports .... Multiple sclerosis in north east Scotland. Health Bull (Edinb) 1984;42/3:1561-6.

2 Hargreaves ER. Epidemiological studies in Cornwall. Proc RSM 1961;54:209-16.

13 Williams ES, McKeran RO. Prevalence of multiple sclerosis in a south London borough. $B M J 1986 ; 293: 237-9$.

14 Swingler RJ, Compston D. The distribution of multiple sclerosis in the United Kingdom. J Neurol Neurosurg Psychiatry 1986;49:1115-24.

15 The Registrar General's Statistical Review of England $\mathbb{E}$ Wales, Scotland and Northern Ireland, 1953-1973. London, Edinburgh and Belfast: HMSO.

16 Mortality Statistics Series. Office of Population Censuses and Surveys; General Register Office (Scotland); General and Surveys; General Register Office (Scotland); General Register Office (Northern Ireland),

17 Annual Abstract of Statistics. Central Statistical Office; 1953-1983; London: HMSO.

18 McCullagh P, Nelder JA. Generalised Linear Models. London: Chapman and Hall, 1983.

19 Breslow NE, Lubin JH, Langholz B. Multiplicative models and cohort studies. J Amer Statist Assoc 1983;78:1-12.

20 Berry $G$. The analysis of mortality by the subject years method. Biometrics 1983;39:173-84.

21 Kuper LL, Janis JM, Karmous A, Greenberg BG. Statistical age-period-cohort analysis: a review and critique. J Chron Dis 1985;38:811-30.

22 Holford TR. An alternative approach to statistical ageperiod-cohort analysis. J Chron Dis 1985;38:831-6.

23 Acheson ED. The pattern of the disease. Matthews WB Acheson ED, Batchelor JR, Weller RO eds. McAlpine's multiple sclerosis. Edinburgh: Churchill Livingstone 1985:3-26.

24 Office of Population Surveys and Censuses. Personal communication.

25 Scottish Registrar General. Personal communication. 